\title{
Scale Effects on Fire Properties of Materials
}

\author{
A. TEWARSON and J. S. NEWMAN \\ Factory Mutual Research Corporation \\ 1151 Boston-Providence Turnpike \\ Norwood, Massachusetts 02062, USA
}

\section{ABSTRACT}

The scale effects on fire properties have been examined for materials in pool-like, box-like, and crib-like configurations.

For turbulent fires of a material, with varying sizes and geometrical arrangements, a chemical similarity was found for each specified value of ventilation and decomposition mode. The decomposition mode in the combustion of the material was found to be important for the production of $c 0$ and particulates.

\section{INTRODUCTION}

Mathematical fire models are now available to evaluate the fire performance of materials in buildings and to estimate the hazards presented by such fires and required protection. Fire models require numerous input parameters, some related to materials and others related to environment. The input parameters are generally quantified in small-scale experiments; it is thus necessary that fire scale effects (if any) on the parameters be known and corrected accordingly.

Input parameters related to materials are needed by the models to describe: 1) fire initiation and growth; 2) mass flow of fuel vapors from the surface of the material; 3) generation of heat and chemical compounds; 4) light attenuation by particulates; 5) biological and corrosive effects of chemical compounds; and 6) efficiency of fire detection, suppression, and extinguishment.

In this paper, parameters describing the generation rates of heat and chemical compounds, and light attenuation by particulates have been considered.

\section{CONCEPTS}

The concepts have been described in detail elsewhere ${ }^{1-7}$. As the fire scale changes, the mass flow rate of fuel vapors from the surface of the material and generation rates of heat and chemical compounds change. The parameters describing these rates, however, should be independent of the fire 
scale, if fires are turbulent and the decomposition chemistry of the material remains invariant.

The total mass flow rate of the mixture of fire products and air, $\dot{m}_{t}$, can be expressed as:

$$
\dot{\mathrm{m}}_{\mathrm{t}}=\dot{\mathrm{m}}_{\mathrm{a}}+\dot{\mathrm{m}}_{\mathrm{f}},
$$

where $\dot{\mathrm{m}}_{\mathrm{a}}=$ mass $\mathrm{flow}$ rate of air $(\mathrm{g} / \mathrm{s})$; and $\dot{\mathrm{m}}_{\mathrm{f}}=$ mass flow rate of fuel vapors $(\mathrm{g} / \mathrm{s})$. If we express the ratio between $\dot{\mathrm{m}}_{\mathrm{f}}$ and $\dot{\mathrm{m}}_{t}$ as $\mathrm{x}_{\mathrm{f}}$, then the following relationships can be derived for the generation rates of heat and chemical compounds:

$$
\begin{gathered}
\dot{G}_{j}=X_{j} \dot{m}_{t}=Y_{j} X_{f} \dot{m}_{t}, \\
\dot{Q}_{A}=\left(H_{T} / k_{j}\right) X_{j} \dot{m}_{t}=\left(H_{T} / k_{j}\right) Y_{j} X_{f} \dot{m}_{t},
\end{gathered}
$$

and,

$$
\dot{\mathrm{Q}}_{\mathrm{C}}=\mathrm{X}_{\mathrm{C}} \mathrm{H}_{\mathrm{T}} \mathrm{X}_{\mathrm{F}} \dot{\mathrm{m}}_{\mathrm{t}}=\Delta \mathrm{T} \mathrm{c}_{\mathrm{p}} \dot{\mathrm{m}}_{\mathrm{t}}
$$

where, $\dot{G}_{j}=$ mass generation of a chemical compound $(g / s) ; X_{j}=$ mass fraction of the compound $(\mathrm{g} / \mathrm{g}) ; Y_{j}=$ mass of the compound generated per unit mass of the fuel vapors defined as the yield of the chemical compound $(\mathrm{g} / \mathrm{g}) ; \dot{\mathrm{Q}}_{\mathrm{A}}$ = generation rate of heat associated with chemical reactions in the fire, defined as the actual heat release rate ( $\mathrm{kW}$ ); in $\mathrm{Eq}$ ( 3 ), compound $\mathrm{j}$ is associated with complete combustion; $\mathrm{H}_{\mathrm{T}}=$ net theoretical heat of complete combustion per unit mass of the fuel vapors $(\mathrm{kJ} / \mathrm{g}) ; \mathrm{k}_{j}=\operatorname{maximum}$ possible theoretical yield of the compound $(\mathrm{g} / \mathrm{g}) ; \dot{\mathrm{Q}}_{\mathrm{C}}=$ convective heat release rate $(\mathrm{kW}) ; x_{c}=$ convective component of combustion efficiency; and $c_{p}=$ average specific heat of the mixture of fire products and air at the gas temperature $(\mathrm{kJ} / \mathrm{g} \mathrm{K})$.

The theoretical heat release rate, $\dot{\mathrm{Q}}_{\mathrm{T}}$, and the theoretical generation rate of a chemical, $\dot{\mathrm{G}}_{\mathrm{T} j}$, can be expressed as

$$
\begin{aligned}
& \dot{\mathrm{Q}}_{\mathrm{T}}=\mathrm{H}_{\mathrm{T}} \mathrm{x}_{\mathrm{f}} \dot{\mathrm{m}}_{\mathrm{t}} . \\
& \dot{\mathrm{G}}_{\mathrm{T} \mathrm{j}}=\mathrm{k}_{j} \mathrm{x}_{\mathrm{f}} \dot{\mathrm{m}}_{\mathrm{t}} .
\end{aligned}
$$

The combustion efficiency, $x_{A}$, is defined as the ratio between $\dot{Q}_{A} / \dot{Q}_{\mathrm{T}}$, and the generation efficiency of a chemical compound, $f_{j}$, is defined as the ratio between $\dot{G}_{j}$ and $\dot{G}_{\mathrm{Tj}}$. Thus

$$
X_{A}=f_{j}=Y_{j} / k_{j}
$$

Equation (7) implies that the ratios between various molecules of chemical compounds generated in the fire are conserved for various degrees of completeness of combustion. From Eqs (3) and (7): 


$$
\dot{\mathrm{Q}}_{\mathrm{A}}=\mathrm{H}_{\mathrm{T}} \mathrm{X}_{\mathrm{A}} \mathrm{x}_{\mathrm{f}} \dot{\mathrm{m}}_{\mathrm{t}}=\mathrm{H}_{\mathrm{T}} \mathrm{f}_{\mathrm{j}} \mathrm{x}_{\mathrm{f}} \dot{m}_{\mathrm{t}}
$$

In Eqs (4) and (8) $x_{C} H_{T}$ and $x_{A} H_{T}$ can be defined as convective and actual heat of combustion $\left(\mathrm{H}_{\mathrm{C}}\right.$ and $\mathrm{H}_{\mathrm{A}}$ respectively). In a similar fashion, $x_{\mathrm{R}} \mathrm{H}_{\mathrm{T}}$ can be defined as the radiative heat of combustion, $H_{R}$, where $x_{R}$ is the radiative component of the combustion efficiency. as

The fraction of light attenuated by particulate, $\mathrm{I} / \mathrm{I}_{0}$, can be expressed

$$
D=\sigma_{\lambda}=\xi_{\lambda} \mathrm{X}_{\mathrm{S}} \rho_{\mathrm{T}}=\xi_{\lambda} \mathrm{Y}_{\mathrm{S}} \mathrm{X}_{\mathrm{f}} \rho_{\mathrm{T}}
$$

where $D=(1 / \ell)$ In $\left(I_{0} / I\right)$, defined as the optical density per unit path length $\ell ; \sigma_{\lambda}=$ extinction coefficient of particulates $\left(\mathrm{m}^{-1)} ; \xi_{\lambda}=\right.$ specific extinction coefficient of particulates $\left(\mathrm{m}^{2} / \mathrm{g}\right) ; \rho_{\mathrm{T}}=$ density of fire products and air $\left(\mathrm{g} / \mathrm{m}^{3}\right)$; and $\lambda=$ wave length of light $(\mu)$.

In order to examine the scale effects on the parameters, experiments can be performed at various fire scales and measurements made for $\dot{m}_{f}, \dot{G}_{j}, \dot{Q}_{C}$, and D. The accuracy of such an examination can be enhanced if the fire products and air, downstream of the reaction zone of the fire, are captured and are well mixed before the analytical measurements.

If the fire products and air are distributed nonuniformly and if heat losses and $\dot{m}_{t}$ values are unknown, such as in enclosure fires, then interrelationships between $\dot{m}_{f}, \dot{G}_{j}, \dot{Q}_{C}$, and $D$ are needed for examining the scale effects.

2.1 Interrelationships Between Mass Flow Rate of Fuel Vapors, Generation Rates of Heat and Chemical Compounds, and Light Attenuation by Particulates

From Eqs (2), (4), and (7)

$$
\begin{aligned}
\Delta \mathrm{T} / \mathrm{X}_{\mathrm{j}} & =\left(1 / \mathrm{c}_{\mathrm{p}}\right)\left(\mathrm{H}_{\mathrm{T}} / \mathrm{k}_{j}\right)\left(\mathrm{x}_{\mathrm{C}} / \mathrm{f}_{\mathrm{j}}\right) \\
& =\left(1 / \mathrm{c}_{\mathrm{p}}\right)\left(\mathrm{H}_{\mathrm{T}} / \mathrm{k}_{j}\right)\left(x_{\mathrm{C}} / \mathrm{x}_{\mathrm{A}}\right),
\end{aligned}
$$

where $j$ is a compound produced (or consumed) in those reactions where heat is also produced. For example, for oxygen $f_{0}$ is defined as the depletion efficiency of oxygen.

From Eqs (2) and (9):

$$
D / X_{j}=\xi_{\lambda} \rho_{T}\left(Y_{S} / Y_{j}\right)
$$

From Eqs (4) and (9):

$$
\Delta \mathrm{T} / \mathrm{D}=\left(1 / \xi_{\lambda} c_{\mathrm{P}} \rho_{\mathrm{T}}\right)\left(x_{\mathrm{C}} / \mathrm{f}_{\mathrm{s}}\right)\left(\mathrm{H}_{\mathrm{T}} / \mathrm{k}_{\mathrm{S}}\right) .
$$


In turbulent fires, $\Delta \mathrm{T} / \mathrm{X}_{\mathrm{j}}, \mathrm{D} / \mathrm{X}_{\mathrm{j}}$, and $\Delta \mathrm{T} / \mathrm{D}$ would be expected to be conserved from one location to another, because various ratios between $\mathrm{H}_{\mathrm{T}}, x_{i}$, $k_{j}, f_{j}, Y_{j}, Y_{S}$, and $\xi_{\lambda}$ are conserved. For turbulent fires, the radiative component of the combustion efficiency, $x_{R}$, is also expected to be conserved.

In enclosure fires, $\Delta \mathrm{T}, \mathrm{X}_{j}$, and $\mathrm{D}$ can be measured at various locations and the scale effects can be examined using Eqs (10) to (12), irrespective of mixing and dilution of the chemical compounds. However, in the analyses, it is necessary to differentiate between effects related to fire scale, to fire chemistry, and to heat losses.

2.2 Factors Affecting the Mass Flow Rate of Fuel Vapors, Generation of Heat and Chemical Compounds, and Light Attenuation by Particulates

2.2.1 Fire Scale. Fire scale affects the mass flow rate of fuel vapors from the surface of the material, due to variations in the flame radiative heat flux, $\dot{q}_{\mathrm{fr}}$. As fire scale increases, $\dot{q}_{\mathrm{fr}}$ and the corresponding value. of the mass flow rate of fuel vapors per unit surface area of the material, $\dot{m}_{f}^{\prime \prime}$, increase and finally approach their asymptotic values; $\dot{m}_{f}^{\prime \prime}$ also increases with the external heat flux, $\dot{q}^{\prime \prime}$. Variations in the oxygen concentration of the environment also affect $\dot{q}_{\mathrm{fr}}^{*}$ and $\dot{m}_{\mathrm{f}}^{\prime \prime}$. When the oxygen concentration in the environment is decreased below the ambient value, $\dot{m}_{\ddot{f}}$ and $\dot{q}_{\text {fr }}$ decrease until the flame extinction $1 \mathrm{imit}$ is reached. When the oxygen concentration in the environment is increased above the ambient value, $\dot{m}_{\mathbf{f}}$ and $q_{\text {f }}$ increase until. they reach their respective asymptotic values (oxygen concentration greater than about 30 percent with a material surface area of about $\left.0.008 \mathrm{~m}^{2}\right) .^{3}$

2.2.2 Fire chemistry. Fire chemistry is affected by fire ventilation. We define a ventilation parameter, $\phi$, as

$$
\phi=\dot{\mathrm{m}}_{\mathrm{a}} / \dot{\mathrm{m}}_{\mathrm{f}} \mathrm{k}_{\mathrm{a}}
$$

where $\mathrm{k}_{\mathrm{a}}$ = theoretical mass of air consumed per unit mass of fuel vapors, also defined as the stoichiometric mass air-to-fuel ratio (g/g).

When $\phi>1$, fires are defined as we11 ventilated and when $\phi<1$, fires are defined as underventilated. From Eqs (1) and (13):

$$
\mathrm{x}_{\mathrm{f}}=1 /\left(1+\mathrm{k}_{\mathrm{a}} \phi\right)
$$

The parameters, $H_{i}, X_{i}, Y_{j}, f_{j}$, and $\xi_{\lambda}$, are strong functions of the chemical structure of the material, as well as the decomposition processes followed by the material at various fire stages. In turbulent fires, these parameters are expected to be conserved for noncharring materials but vary with the extent of char formation, at various fire stages, for the char-forming materials.

2.2.3 Heat Losses. Values of $\Delta \mathrm{T}$ are affected by heat losses. Laboratory-scale experiments can be designed such that heat losses are negligibly small. In enclosure fires, the heat losses could be quite significant, and, if the losses are not accounted for, then $\Delta T$ values would be in error. 
Furthernore, in laboratory-scale experiments the distribution of $\dot{Q}_{A}$ into $\dot{Q}_{C}$ and $\dot{Q}_{R}$ can be quantified quite accurately, whereas in enclosure fires this distribution is not well defined. The distribution, however, can be defined in terms of the heat flow out of the enclosure, $\dot{Q}_{g}$, and heat lost within the enclosure, $\dot{Q}_{l}$. The relationship developed for $\dot{Q}_{C}$ and $\chi_{C}$ will still apply to $\dot{Q}_{g}$ and $\chi_{g}$ (combustion efficiency component associated with the temperature of the gas lowing out of the enclosure).

\section{EXPERIMENTS}

Experiments were performed in three combustibility apparatuses: a $10-\mathrm{kW}^{1-7}$ scale, a $500-\mathrm{kW}$ scale $^{8}$, and a $5000-\mathrm{kW}$ scale apparatus ${ }^{9}$.

In the apparatuses, the mass flow rate of the fuel vapors is monitored. The fire products are diluted and well mixed with ambient air as they are captured in the sampling ducts of each apparatus. The maximum flow rates of the mixture of fire products and ait used in the 10-, 500-, and 5000-kW scale apparatuses are about $0.03,2.0$, and $28 \mathrm{~m}^{3} / \mathrm{s}$ respectively. The measurements made in the sampling ducts include: total mass and volumetric flow rate of the mixture of fire products and air; gas temperature; light attenuation by particulates*; and concentration of $\mathrm{CO}_{2}, \mathrm{CO}$, hydrocarbons, and water* The output from all the instruments is stored and analyzed by a computer.

\section{RESULTS}

\subsection{Physical Similarity in Terms of Mass Flow Rate of Fuel Vapors from the} Surface of the Material

The average steady state values of $\dot{m}_{\mathrm{f}}$, including the asymptotic values obtained by increasing either the surface area of the material or by increasing the oxygen concentration in the environment are listed in Table.1. A reasonable agreement can be noted between the asymptotic values of $\dot{m}_{\tilde{f}}$ obtained by two different types of experiments. The data in Table 1 suggest that the fire scale effects on $\dot{m}_{f}$ due to flame radiative heat flux can be compensated in the laboratory-scale fires by using either oxygen concentration in the environment greater than the ambient value or by using external heat flux.

\subsection{Chemical Similarity in Terms of $\mathrm{H}_{i}, \mathrm{Y}_{j}$, and $\xi_{\lambda} \mathrm{Y}_{\mathrm{s}}$}

The data for $H_{i}, Y_{j}$, and $\xi_{\lambda} Y_{s}$ are listed in Tables 2 and 3 . An examination of the data indicates that, within the experimental variation of the data, there is a chemical similarity between various scale fires of each material under a specified mode of decomposition for well ventilated fires. For cellulosic material, flaming mode is defined as the initial fire stage, where flames are relatively taller; flaming/smoldering mode is defined as a mode which follows the initial flaming mode. In the flaming/smoldering mode, flames are relatively shorter accompanied by surface glowing; flames are intermittent and do not cover the entire surface of the material.

\footnotetext{
* not measured in the $5000-\mathrm{kW}$ scale apparatus
} 
TABLE 1. Average Steady State Values of the Mass Flow Rate of Fuel Vapors per Unit Surface Area of the Material ${ }^{a}$

Materia1

Pool-1ike Configuration

$\begin{array}{ll}\text { Polyethylene/42\% Chlorine } & 0.008 \\ \text { Polyvinyl Chlortde } & 0.008 \\ \text { Polyoxymethylene } & 0.008 \\ \text { Methanol. } & 0.008 \\ & 2.37 \\ \text { Elexible polyurethane foams } & 0.008 \\ \text { Rigid polyurethane foams } & 0.008 \\ \text { Polypropylene } & 0.008 \\ \text { Polyethylene } & 0.008 \\ \text { High temp. hydrocarbon fluids } & 0.008 \\ & 2.37 \\ \text { Polymethylmethacrylate } & 0.008 \\ & 2.37 \\ \text { Polystyrene } & 0.008 \\ & 0.93 \\ \text { Heptane } & 0.008 \\ & 1.17\end{array}$

Three-Dimensional Arrangement

Corrugated paper boxes wh th shredded paper

Corrugated paper boxes with a foam

Pine wood cribs

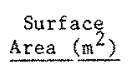

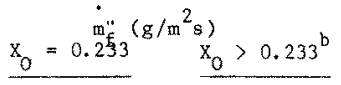

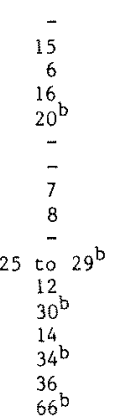

$\begin{array}{cc} & \\ - & 7 \\ 15 & 16 \\ 6 & 16 \\ 16 & 20 \\ 20^{b} & - \\ - & 21 \text { to } 27 \\ - & 22 \text { to } 25 \\ 7 & 24 \\ 8 & 26 \\ - & 27 \text { to } 30 \\ 25 \text { to } 29^{\mathrm{b}} & - \\ 12 & 28 \\ 30^{\mathrm{b}} & - \\ 14 & 38 \\ 34^{\mathrm{b}} & - \\ 36 & 63 \\ 66^{\mathrm{b}} & -\end{array}$

a no external heat flux unless specified;

b asymptotic value;

- total exposed surface area of single box $(0.1 \times 0.1 \times 0.1 \mathrm{~m})$;

d total exposed surface area of sixteen boxes (four boxes on one pallet load, two pallet load wide $x$ two pallet load deep $x$ two tiers high, each box dimensions $0.53 \times 0.53 \times 0.53 \mathrm{~m})$;

e $25 \mathrm{~kW} / \mathrm{m}^{2}$ of external heat flux on four sides.

For cellulosic materials, chemical similarity in terms of $\mathrm{H}_{i}$ and $\mathrm{X}_{\mathrm{CO}}$ is maintained for both flaming and flaming/smoldering modes. Chemical similarity in terms of $\mathrm{Y}_{\mathrm{CO}}$ and $\xi_{\lambda} \mathrm{Y}_{\mathrm{S}}$, however, is maintained only if the decomposition mode does not change. For example, the average value of $\mathrm{Y}_{\mathrm{CO}}=0.0059 \mathrm{~g} / \mathrm{g}$ in the flaming mode (except for cellulose and densely packed paper box) and $0.097 \mathrm{~g} / \mathrm{g}$ for the flaming/smoldering mode. The average value of $\xi_{\lambda_{2}} \mathrm{Y}_{\mathrm{S}}$ in the flaming mode is $0.0075 \mathrm{~m}^{2} / \mathrm{g}$ for cellulose and paper box and $0.078 \mathrm{~m}^{2} / \mathrm{g}$ for oak, fir, and pine. In the flaming/smoldering mode, the average value of $\xi_{\lambda}$ $\mathrm{Y}_{\mathrm{S}}=0.67 \mathrm{~m}^{2} / \mathrm{g}$ for paper box, $0.013 \mathrm{~m}^{2} / \mathrm{g}$ for cellulose, and $0.15 \mathrm{~m}^{2} / \mathrm{g}$ for pine-wod crib. In oxidative-pyrolysis, the average value of $\xi_{\lambda} Y_{S}=$ $0.80 \mathrm{~m}^{2} / \mathrm{g}$ for oak and pine. 
TABLE 2. Average Yields of $\mathrm{CO}_{2}, \mathrm{CO}$, and $\mathrm{HCN}$ and Heat of Combustion for Well Ventilated Fires of Materials in Pool-Like Configuration

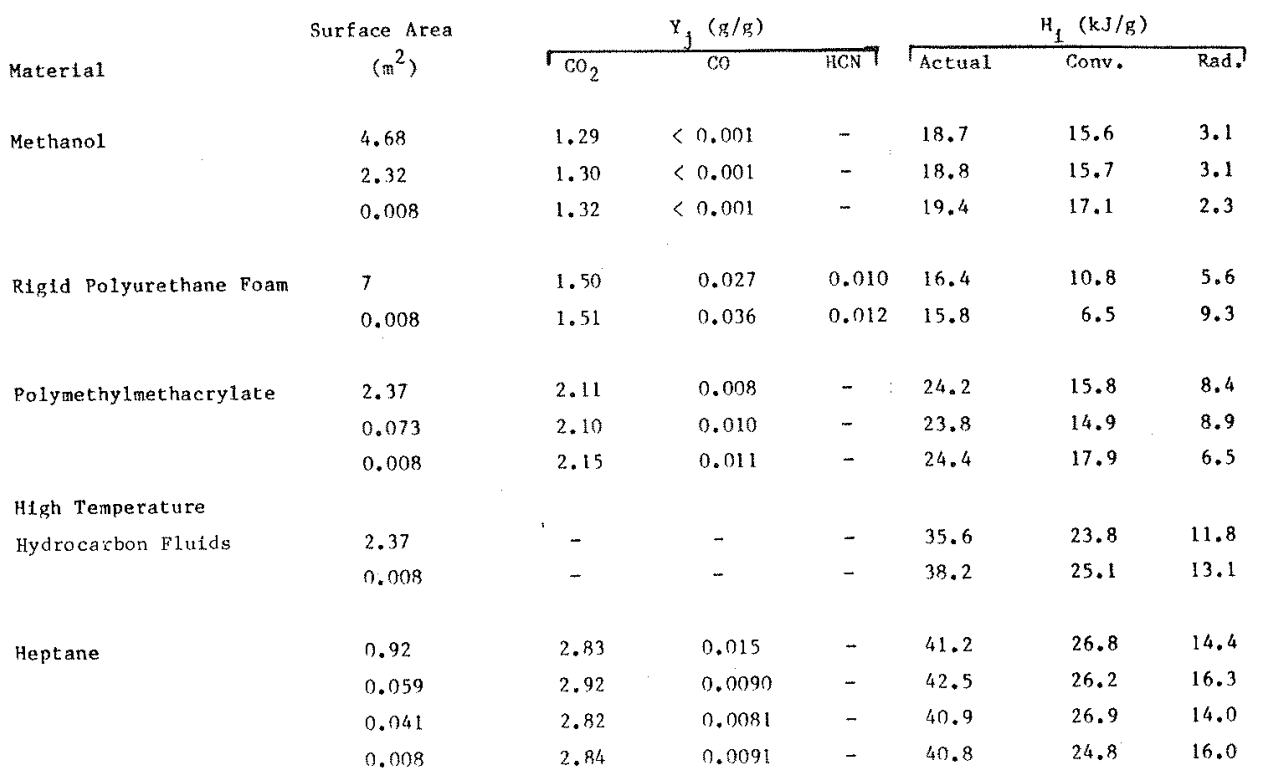

4.3 Chemical Similarity in Terms of the Ratios of Generation Rates of Heat and Chemical Compounds, Light Attenuation by Particulates, and Depletion Rate of Oxygen

The generation of $\mathrm{CO}_{2}$ and depletion of $\mathrm{O}_{2}$ are associated with the generation of heat; an interrelationship between $\Delta \mathrm{T}, \mathrm{X}_{\mathrm{CO}_{2}}$, and $\mathrm{X}_{\mathrm{O}}$ is thus expected:

$$
\frac{\left(\Delta \mathrm{T} / \mathrm{T}_{\mathrm{a}}\right) /\left(\mathrm{X}_{\mathrm{CO}_{2}}-\mathrm{X}_{\mathrm{CO}_{2}, \mathrm{a}}\right)}{\left(\Delta \mathrm{T} / \mathrm{T}_{\mathrm{a}}\right) /\left(\mathrm{X}_{\mathrm{Oa}}-\mathrm{X}_{\mathrm{O}}\right)}=\left(\mathrm{k}_{\mathrm{O}} / \mathrm{k}_{\mathrm{CO}_{2}}\right)\left(\mathrm{f}_{\mathrm{O}} / \mathrm{f}_{\mathrm{CO}_{2}}\right)
$$

where $\mathrm{X}_{\mathrm{CO}_{2}}$ and $\mathrm{X}_{\mathrm{O}}=$ measured mass fractions of $\mathrm{CO}_{2}$ and $\mathrm{O}_{2}$ respectively; $\mathrm{X}_{\mathrm{CO}}$, a and $\mathrm{X}_{\mathrm{Oa}} \stackrel{=}{=}$ measured ambient mass fractions of $\mathrm{CO}_{2}$ and $\mathrm{O}_{2}$ respectively; $\mathrm{k}_{0}$ and $\mathrm{k}_{\mathrm{CO}}$ can be calculated from the measured elemental compositions of the materiałs. Chemical similarity in terms of $\mathrm{f}_{\mathrm{O}} / \mathrm{f}_{\mathrm{CO}}$ thus can be established for various fire scales, irrespective of mixing and dilution of the compounds.

Our laboratory-scale data indicate that $\mathrm{f}_{0} / \mathrm{f}_{\mathrm{CO}}$ is conserved for numerous materials that we have examined, under a variety of 2 experimental conditions, where $f_{0}=0.98 \mathrm{f}_{\mathrm{CO}_{3}}$. The data shown in Figure 1 , for the enclosure fires of wood cribs under a tariety of ventilation conditions, enclosure sizes, and crib sizes support our conclusion.

The data for $\mathrm{f}_{\mathrm{O} / \mathrm{f}_{\mathrm{CO}}}$ indicate a strong dependency on the chemical structure of the material, decomposition chemistry, and fire ventilation; the effect of ventilation on this ratio is shown in Figure 2 for pine wood crib fires in enclosures and in our 10-kw scale apparatus. Data for cellulose and red oak have also been included in the figure. The data in Figure 2 indicate that $f_{0} / f_{C O}$ is conserved for each value of $\dot{X}_{f}$ for various fire scales. With 
TABLE 3. Average Yields of $\mathrm{CO}_{2}$, $\mathrm{Co}$, and Gaseous Hydrocarbons, Heat of Combustion, and Specific Extinction Coefficient for Well Ventilated Fires of Cellulosic Materials

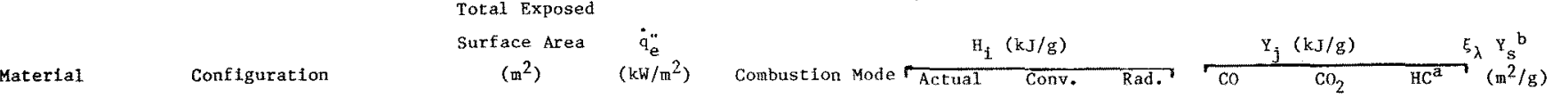

Corrugated Paper Box with sheets of paper (25\% by weight)

Corrugated Paper Box with shredded paper ( $62 \%$ by weight)

\begin{tabular}{|c|c|c|c|c|c|c|c|c|c|c|}
\hline 0.06 & & 0 & Flaming & 11.1 & 9.4 & 1.7 & 0.0082 & 1.12 & c & 0.0053 \\
\hline \multirow[t]{8}{*}{0.06} & & 0 & Nlaming & 12.4 & 9.0 & 3.4 & 0.019 & 1.25 & 0.001 & 0.0067 \\
\hline & & & Flaming/Strold. & 10.8 & 6.8 & 4.0 & 0.12 & 1.11 & 0.002 & 0.062 \\
\hline & & 10 & Flaming & 11.6 & 8.7 & 2.9 & 0.021 & 1.17 & 0.001 & 0.0067 \\
\hline & & & Flaming/Smold. & 11.2 & 6.8 & 4.4 & 0.091 & 1.16 & 0.002 & 0.065 \\
\hline & & 21 & Flaming & 9.9 & 7.9 & 2.0 & 0.030 & 1.00 & c & 0.0062 \\
\hline & & & Flaming/Smold. & 11.4 & 7.2 & 4.2 & 0.091 & 1.18 & 0.004 & 0.058 \\
\hline & & 31 & Flaming & 11.4 & 8.0 & 3.4 & 0.018 & 1.16 & 0.001 & 0.012 \\
\hline & & & Flaming/Smold. & 11.8 & 7.8 & 4.0 & 0.110 & 1.27 & 0.021 & 0.082 \\
\hline 53 & & 0 & Flaming & 12.3 & 9.2 & 3.1 & 0.0085 & 1.25 & c & ND \\
\hline 0.007 & & 50 & Flaming & 12.8 & 9.1 & 3.7 & 0.0021 & 1.29 & c & 0.0057 \\
\hline 0.007 & & 50 & Flaming/Smold. & 10.2 & 5.8 & 4.3 & 0.095 & 1.05 & 0.001 & 0.013 \\
\hline \multirow[t]{3}{*}{0.007} & 31 & to 71 & Flaming & 13.3 & 7.8 & 5.5 & 0.0039 & 1.34 & c & 0.086 \\
\hline & & & Oxid. Pyrolysis & $\mathrm{NA}$ & NA & $\mathrm{NA}$ & 0.096 & 0.14 & 0.041 & 0.85 \\
\hline & & & Pyrolysis & NA & $\mathrm{NA}$ & NA & 0.054 & 0.12 & 0.029 & 0.91 \\
\hline 0.007 & & to 60 & Flaming & 13.0 & 8.1 & 4.9 & 0.0036 & 1.31 & c & 0.084 \\
\hline \multirow[t]{3}{*}{0.062} & 0 & to 60 & Flaming & 12.2 & 8.7 & 3.5 & 0.0054 & 1.31 & c & 0.064 \\
\hline & & & Flaming/Smold. & 10.7 & 8.0 & 2.7 & 0.092 & 1.18 & 0.019 & 0.15 \\
\hline & & & Oxid. Pyrolysis & NA & $\mathrm{NA}$ & $\mathrm{NA}$ & 0.18 & 0.23 & 0.060 & 0.68 \\
\hline
\end{tabular}

a Total gaseous hydrocarbons

b $\lambda=0.63 \mu$

c $<0.001$

d 16 boxes, four boxes on one pallet load; 2 pallets wide $\times 2$ pallet loads deep $\times 2$ tiers high No not deternined 


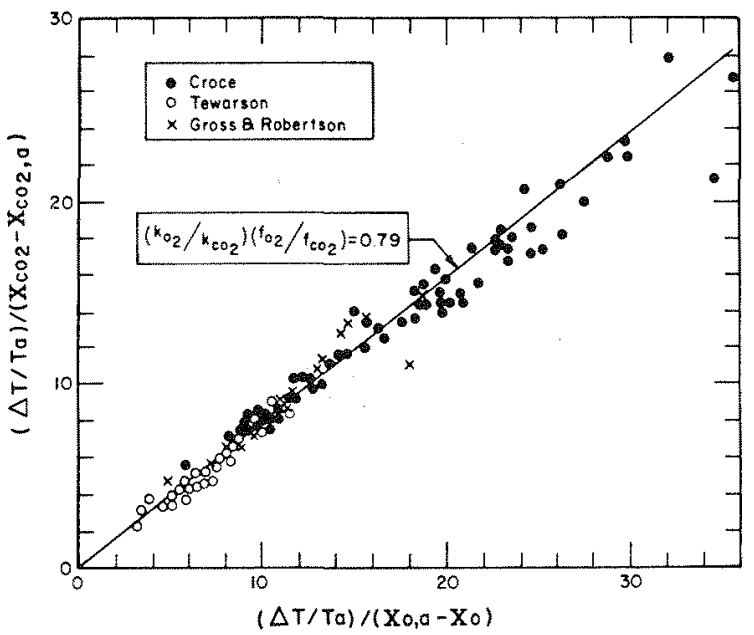

F LGURE 1. Chemical similarity in terms of the ratio of generation efficiency of $\mathrm{CO}_{2}$ and depletion efficiency of $\mathrm{O}_{2}$. Solid line is theoretical relationship, Experimental data taken from Refs. 10-12. Enclosure sizes from 0.21 to $22 \mathrm{~m}^{3}$; exposed surface areas of cribs from 0.062 to $11 \mathrm{~m}^{2}$.

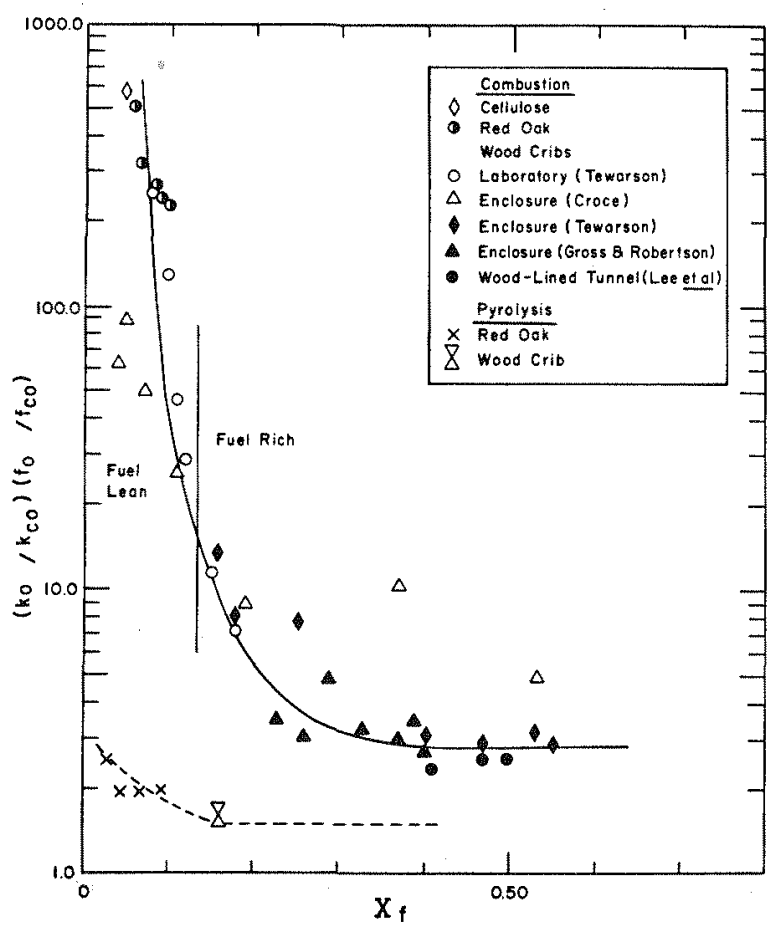

FIGURE 2. Dependency of the ratio of depletion efficiency of $\mathrm{O}_{2}$ and generation efficiency of $C O$ on fuel richness of the fire (Pyrolysis $\mathrm{x}_{0}=0.11$ ). 
increasing values of $\mathrm{X}_{f}$ (fire conditions changing from well ventilated to underventilated), $\mathrm{f}_{\mathrm{O}} / \mathrm{f}_{\mathrm{CO}}$ approaches an asymptotic value (about 2.3 for combustion and about 1.2 for oxidative pyrolysis, for $\left.x_{f}>0.3\right)$. If we assume $x_{0}=$ 0 , then the values of $f_{C O}$ and $Y_{C O}$ would be about 0.4 and $0.5 \mathrm{~g} / \mathrm{g}$ in combustion and about 0.8 and $1.0 \mathrm{~g} / \mathrm{g}$ in oxidative pyrolysis respectively. The maximum possible theoretical yield of co for wood is $1.23 \mathrm{~g} / \mathrm{g}$.

The relationship between $\xi_{\lambda} \mathrm{Y}_{\mathrm{S}}$, and $\mathrm{X}_{\mathrm{f}}$ is shown in Figure 3 , where data for pine wood cribs from enclosure fires and from our 10-kW scale apparatus, together with cellulose and paper, have been included. The $\xi_{\lambda} Y_{S}$ values for paper products are lower than the value for pine wood crib under natural air flow. With increasing value of $x_{f}, \xi_{\lambda} Y_{S}$ values for red oak and pine wood crib increase, reaching a maximum value of about $0.12 \mathrm{~m}^{2} / \mathrm{g}$ for $0.13 \mathrm{~g} / \mathrm{g}\left\langle\mathrm{X}_{\mathrm{f}}\right\rangle$ $0.20 \mathrm{~g} / \mathrm{g}$, indicating a maximum generation efficiency of particulates at this slightly fuel rich condition (for stoichiometric combustion of pine wood crib, $\left.\mathrm{X}_{\mathrm{f}}=0.13 \mathrm{~g} / \mathrm{g}.\right)$ For $\mathrm{X}_{\mathrm{f}}>0.20 \mathrm{~g} / \mathrm{g}$, in the enclosure fires of pine wood cribs, $\xi_{\lambda} Y_{S}$ decreases with increase in $X_{f}$, lndicating a decrease in particulate formation. This suggests that the major fraction of the carbon in the fue 1 vapors is converted into the oxygenated species as $\mathrm{x}_{\mathrm{f}}$ increases in the enclosure fires, which is in agreement with the conclusion derived previously ${ }^{6}$ on the basis of the carbon atom balance.

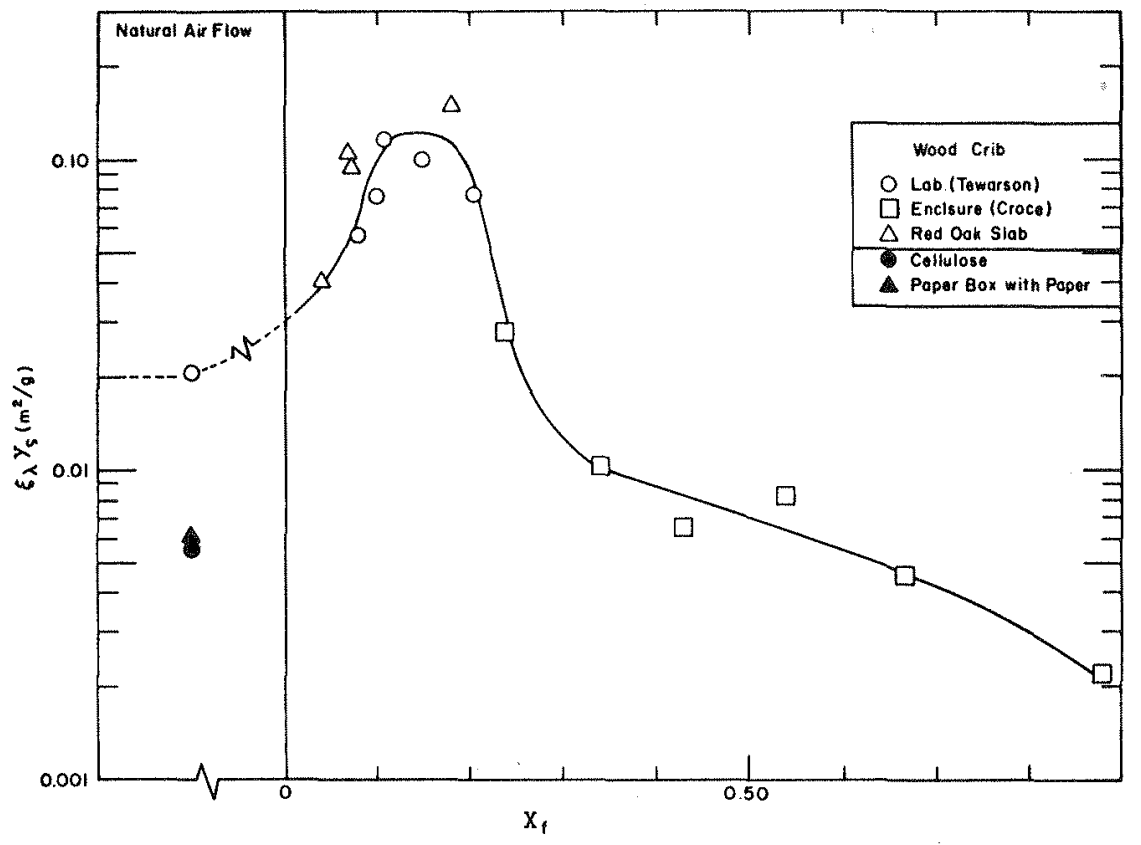

FIGURE 3. Dependency of the specific extinction coefficient of particulates on fuel richness of the fire. 
1. Experimental results obtained from the 10-, 500-, and 5000-kW scale apparatuses and enclosure fires of various sizes, for materials in poo1like, box-like and crib-like configurations, suggest that in turbulent fires of each material, under a specified value of the ventilation parameter and mode of decomposition, chemical similarity is maintained in terms of combustion efficiency and generation efficiency of chemical compounds and specific extinction coefficient of particulates.

2. The generation efficiency of CO and extinction coefficient of particulates was found to be very sensitive to the decomposition mode of cellulosic materials. The combustion efficiency and the generation efficiency of $\mathrm{CO}_{2}$ was found to be less sensitive to the decomposition mode.

3. In the laboratory-scale experiments, it was possible to compensate the fire scale effects due to flame radiation by increasing the oxygen concentration in the environment above the ambient value.

4. The specific extinction coefficient of particulates for wood was found to reach a maximum value of about $0.12 \mathrm{~m}^{2} / \mathrm{g}$ under slightly fuel-rich conditions.

5. The maximum possible yield of co from wood fires was estimated to be about $0.5 \mathrm{~g} / \mathrm{g}$ in combustion and about $1.0 \mathrm{~g} / \mathrm{g}$ in oxidative pyrolysis.

\section{ACKNOWLEDGEMENT}

The financial support under Grant No. NB83NADA4021 from the U.S. National Bureau of Standards, Center for Fire Research, Washington, D.C. is deeply appreciated.

\section{REFERENCES}

1 Tewarson, A., "Physico-Chemical and Combustion Pyrolysis Properties of Polymeric Materials," National Bureau of Standards, Washington, D.C. NBS-GCR-80-295 (1980).

2 Tewarson, A., Flame Retardant Polymeric Materials, Volume 3, Lewin, Atlas and Pearce (editors). Plenum Press, New York, (1982).

3 Tewarson, A., Lee, J. L., and Pion, R. F., "The Influence of Oxygen Concentration on Fuel Parameters for Fire Modeling," Eighteenth Symposium (Internationa1) on Combustion, p. 563, The Combustion Institute (1980).

4 Tewarson, A., "Quantification of Fire Properties of Fuels and Interaction with Fire Environment," National Bureau of Standards, Washington, D.C., FMRC J.I. OEON6.RC (1982).

5 Tewarson, A. and Steciak, J., "Fire Ventilation," Combustion and Flame, 53, (1983).

6 Tewarson, A., "Tully Developed Enclosure Fires of Wood Cribs, "Twentieth symposium (International) on Combustion. The Combustion Institute (in press). 
7 Tewarson, A., "Scale Effects on Fire Properties of Materials," National Bureau of Standards, Washington, D.C., FMRC J.I. OJ4N2.RC (1984).

8 Newman, J. S., "Standard Test Criteria for Evaluation of Underground Fire Detection System," U.S. Bureau of Mines, Pittsburgh, PA, FMRC J.I. OG2N4.RC (1984).

9 Heskestad, G., "A Fire Products Collector for Calorimetry into the MW Range," Factory Mutual Research Corporation, Norwood, MA, FMRC J.I. OC 2E1.RA, June (1981).

10 Gross, D. and Robertson, A. F., Experimental Fires in Enclosures," Tenth Symposium (International) on Combustion, p. 931, The Combustion Institute (1965).

11 Tewarson, A., "Some Observations on Experimental Fires in Enclosures - Part I. Cellulosic Materials," Combustion and Flame, 19, 101 (1972).

12 Croce, P. A., "Modeling of Vented Enclosures Fires, Part 1 - Quasi-Steady State Wood Crib Fire," Factory Mutual Research Corporation, Norwood, MA, FMRC J.I. 7AOR5, GU (1978).

13 Lee, C. K., Chaiken, R. F., Singer, J. M. and Harris, M. E., "Behavior of Wood Fires in Model Tunnels under Forced Ventilation Flow," U. S. Bureau of Mines, Pittsburgh, PA, Report of Investigations 8450, 1980, available from Supt. of Docs. No. I28.23:8400. 